OPEN ACCESS

Edited by:

Mohamed Abdel-Mohsen,

Wistar Institute, United States

Reviewed by:

Naeem Khan,

Western Michigan University,

United States

Isaak Quast,

Monash University, Australia

*Correspondence:

Margaret E. Ackerman

margaret.e.ackerman@dartmouth.edu

Specialty section:

This article was submitted to

B Cell Biology,

a section of the journal

Frontiers in Immunology

Received: 06 August 2021 Accepted: 27 September 2021 Published: 12 October 2021

Citation:

Crowley AR, Osei-Owusu NY,

Dekkers G, Gao W, Wuhrer M, Magnani DM, Reimann KA, Pincus SH, Vidarsson G and Ackerman ME (2021) Biophysical Evaluation of Rhesus Macaque Fc Gamma Receptors Reveals Similar IgG FC Glycoform Preferences to Human Receptors.

Front. Immunol. 12:754710. doi: 10.3389/fimmu.2021.754710

\section{Biophysical Evaluation of Rhesus Macaque Fc Gamma Receptors Reveals Similar IgG Fc Glycoform Preferences to Human Receptors}

\author{
Andrew R. Crowley ${ }^{1}$, Nana Yaw Osei-Owusu ${ }^{1}$, Gillian Dekkers ${ }^{2}$, Wenda Gao ${ }^{3}$, \\ Manfred Wuhrer ${ }^{4}$, Diogo M. Magnani ${ }^{5}$, Keith A. Reimann ${ }^{5}$, Seth H. Pincus ${ }^{6,7}$, \\ Gestur Vidarsson ${ }^{2}$ and Margaret E. Ackerman ${ }^{1,8 *}$
}

${ }^{1}$ Department of Microbiology and Immunology, Geisel School of Medicine at Dartmouth, Dartmouth College, Hanover, NH, United States, ${ }^{2}$ Sanquin Research and Landsteiner Laboratory, Academic Medical Centre, Department of Experimental Immunohematology, University of Amsterdam, Amsterdam, Netherlands, ${ }^{3}$ Antagen Pharmaceuticals Inc., Boston, MA, United States, ${ }^{4}$ Center for Proteomics and Metabolomics, Leiden University Medical Center, Leiden, Netherlands, ${ }^{5}$ Nonhuman Primate Reagent Resource, MassBiologics of the University of Massachusetts Medical School, Boston, MA, United States, ${ }^{6}$ Department of Microbiology, Immunology and Parasitology, Louisiana State University Health Sciences Center, New Orleans, LA, United States, ${ }^{7}$ Department of Chemistry and Biochemistry, Montana State University, Bozeman, MT, United States, ${ }^{8}$ Thayer School of Engineering, Dartmouth College, Hanover, NH, United States

Rhesus macaques are a common non-human primate model used in the evaluation of human monoclonal antibodies, molecules whose effector functions depend on a conserved $\mathrm{N}$-linked glycan in the $\mathrm{Fc}$ region. This carbohydrate is a target of glycoengineering efforts aimed at altering antibody effector function by modulating the affinity of Fcy receptors. For example, a reduction in the overall core fucose content is one such strategy that can increase antibody-mediated cellular cytotoxicity by increasing FcFcyRIIla affinity. While the position of the Fc glycan is conserved in macaques, differences in the frequency of glycoforms and the use of an alternate monosaccharide in sialylated glycan species add a degree of uncertainty to the testing of glycoengineered human antibodies in rhesus macaques. Using a panel of 16 human IgG1 glycovariants, we measured the affinities of macaque FcyRs for differing glycoforms via surface plasmon resonance. Our results suggest that macaques are a tractable species in which to test the effects of antibody glycoengineering.

Keywords: nonhuman primate, IgG, Fc gamma receptor, $\mathrm{N}$ glycan, rhesus macaque, ADCC - antibody dependent cellular cytotoxicity, phagocytosis, complement dependent cytotoxicity

\section{INTRODUCTION}

Like many proteins destined for secretion, human immunoglobulin $G(\operatorname{IgG})$ is subject to a variety of post-translational modifications as it migrates through the secretory pathway of plasma cells. A prominent modification is the attachment of an N-linked glycan to both heavy chains in the crystallizable fragment $(\mathrm{Fc})$ portion (1). While the amino acid sequon is conserved, the precise identity of the specific $\mathrm{N}$-linked glycoform incorporated is not genetically encoded. 
Among glycosylated IgG Fc domains, there exist a variety of observed glycoforms - 36 in total for humans (2), eight of which account for $90 \%$ of all IgG in normal sera (3). The frequency of IgG Fc glycoforms within the distribution of the total glycan repertoire tends to be predictable in healthy individuals (4), with some variation due to factors such as age, sex, and pregnancy (511). In general, this profile consists of high levels of fucosylation (95\%), low levels of bisecting GlcNAc (15\%), intermediate levels of galactose (45\%), and low sialylation (10\%) (3). This balance can be perturbed by a heightened immune response however (12, 13), and distinct antigen-specific antibody fractions may differ from each other and from the average serum IgG Fc glycan profile within a given individual (14-16).

Occupancy of this conserved glycosylation site is critical to the ability of an IgG molecule to interact with human Fc $\gamma$ receptors (Fc $\gamma \mathrm{R})$, as the absence or removal of the N-glycan produces an antibody with dramatically diminished or outright eliminated affinity for $\mathrm{Fc} \gamma \mathrm{R}$ and no detectable effector function $(17,18)$. Slight changes in the composition of the Fc glycan can impart changes to the $\mathrm{Fc}-\mathrm{Fc} \gamma \mathrm{R}$ dynamic that may resonate all the way to the severity of clinical presentation (19-27). More specifically, an increase in galactose content has been associated with increased propensity of the $\mathrm{Fc}$ domain to hexamerize (28), as well as with a slight ( $\leq 2$ fold) increase in affinity for most of the low affinity (i.e., not Fc $\gamma R I)$ Fc $\gamma$ Rs $(29,30)$, while the absence of a fucose molecule branching from the asparagine-proximal $\mathrm{N}$-acetylglucosamine (GlcNAc) has been credited with up to an astounding 50 -fold increase in affinity for Fc $\gamma$ RIIIa/b (31-33). This increase in affinity translates to improvement in antibody-dependent cellular cytotoxicity by FcyRIIIa-bearing natural killer (NK) cells $(34,35)$, which has made it an attractive tool for enhancing the efficacy of therapeutic monoclonal antibodies (mAbs) $(36,37)$.

Pre-clinical animal models serve as an important bridge for such glycoengineered mAbs migrating from the lab to the clinic. Like that of humans, macaque IgG features a conserved $\mathrm{N}$-linked glycan motif, which is necessary for binding to macaque Fc $\gamma \mathrm{R}$ $(38,39)$. Despite having a degree of homology to humans that makes them a tractable and popular animal model for biomedical research, like all models, macaques can be sufficiently immunologically distinct that care should be exercised when attempting to extrapolate observations in non-human primates to humans (40). Whereas the macaque IgG subclasses are more functionally monolithic than those in humans (39), genetic diversity among Fc $\gamma \mathrm{R}$ is significantly greater among macaques than in humans, particularly for FcyRII (41). Additionally, macaques do not express an equivalent of the GPI-linked human FcrRIIIb, and the clinically-relevant functional differences in high and low FcyRIIIa binding affinity allotypes observed in humans are not reflected among frequent alleles in macaques (42). These characteristics help to set expectations and guide design and interpretation of experiments conducted in these models. Yet, other aspects of antibody immunobiology have yet to be fully investigated; the impact of antibody glycosylation on receptor binding is one such area of concern. Macaque IgG is more likely to feature a bisecting GlcNAc residue and shows greater variability in galactose content than human $\operatorname{IgG~Fc~}(43,44)$. Furthermore, human IgG Fc sialylation is carried out with $\mathrm{N}$-acetylneuraminic acid (NANA) whereas macaques use N-glycolylneuraminic acid (NGNA) (43). The most striking effect of glycovariation in human IgG is very clearly the "fucose effect" for FcyRIII, which has been proposed to be mediated by disruption of glycan-glycan contacts $(45,46)$ or via altered conformational sampling (47). Regardless of mechanism, this effect is readily observed from mice to humans (48), and the receptor glycosylation site associated with it is conserved in rhesus macaques (38). The available data suggest that the effect of afucosylation on macaque FcyRIIIa affinity is also conserved (49), although perhaps with more modest fold-change increases in affinity than what has been observed in humans.

Using a panel of glycoengineered human IgG1 antibodies, we report the affinities of the low affinity rhesus macaque (RM) Fc $\gamma$ receptors for each of 16 glycoforms, and further validate our observations by analysis of relationships between rhesus serum IgG Fc glycan profiles and Fc $\gamma \mathrm{R}$ binding levels. This work provides a more complete picture of the glycopreferences of macaque Fc $\gamma$ Rs, allowing for more confident design of experiments and interpretation of data when engineered human antibodies are tested in non-human primate models.

\section{RESULTS AND DISCUSSION}

A panel of 16 previously described IgG Fc glycovariants generated via a series of chemical and genetic methods that alter the dominant species of glycan within production runs of an anti-trinitrophenol (TNP) human IgG1 monoclonal antibody (mAb) $(50,51)$ was used to investigate the glycopreferences of rhesus macaque $\mathrm{Fc} \gamma \mathrm{R}$ recognition (Supplemental Table 1). Briefly, these tools selectively achieved a greater than nine-fold reduction in the amount of core fucose (from 95\% to 10\%), a ten-fold or greater increase in the frequency of bisected species (from $5 \%$ to $>50 \%$ ), and terminal sialylation ( $3 \%$ to $>40 \%$ ), as previously reported in greater detail (51). Variation in galactose content ranged from $10 \%$ to $80 \%$. Collectively, this panel of variants represents well the diversity of glycan changes that exist within human serum and in recombinant expressed and glycoengineering monoclonal antibodies.

The affinity of the low affinity macaque Fc $\gamma$ Rs for these variable glycoforms was measured using a multiplexed surface plasmon resonance (SPR) approach in which the glycovariants were covalently linked to a sensor chip and the FcyRs were the analyte in solution. Some of the differences imparted by modulating the Fc glycan were readily apparent from raw sensorgrams (Figure 1). While all the interactions exhibit a fast-on association dynamic, the off-rate was noticeably slower in the case of the higher affinity FcyRIIIa. This observation was particularly striking for interactions with afucosylated IgG wherein dissociation was not always complete by the end of the 5-minute step.

Equilibrium dissociation constants $\left(K_{D}\right)$ were fitted to the responses at steady state to define binding affinities for each 


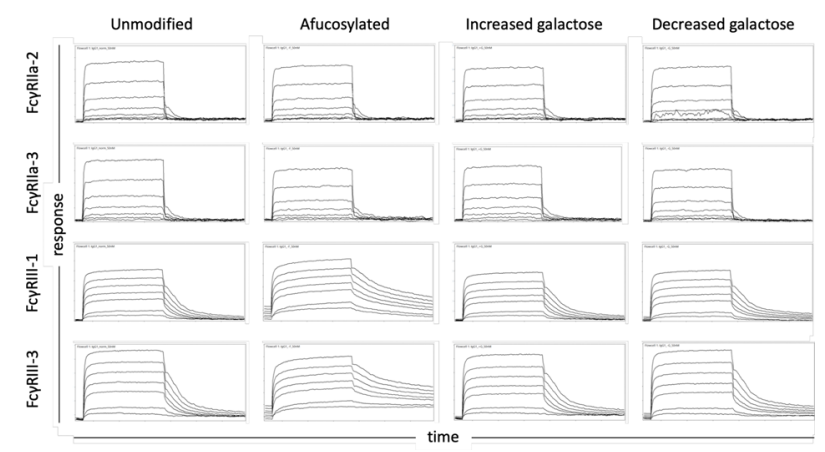

FIGURE 1 | Exemplary sensor data of FcyR-IgG interactions. Sensorgams depicting the association and dissociation of FcyR from lgG over time for prevalent FcyRll (2 and 3) and FcyRIII (1 and 3) allotypes (rows) and differentially glycosylated lgG (columns). The equilibrium dissociation constants reported in this work were calculated using the response measured at the end of the association phase when interactions had achieved steady state. Each receptor was evaluated over a three order of magnitude concentration range.

receptor and IgG Fc glycoform variant in two separate experiments that compared the set of glycovariants with each modification to the set without (Figure 2). Among glycan modifications, reduction in core fucose of human IgG1 resulted in the most dramatic change in receptor binding affinity - improving the affinity of rhesus macaque Fc $\gamma$ RIII as compared to Fc glycoforms without intentionally reduced fucose content (Figure 2A). While there was some variability in the magnitude and statistical confidence in the effect of reduced fucose between experimental runs and across the major FcyR allotypes (Figure 3), these results were generally consistent with a prior report of the sensitivity of RM FcyRIIIa to IgG Fc fucosylation (49).
In contrast, the presence or absence of bisecting GlcNAc did not have a statistically significant effect on the binding affinity of any RM Fc $\gamma$ R tested (Figures 2B, 3). While a prior study suggested that the presence of bisecting GlcNAc resulted in improved effector function in the context of human FcyR (52), other work has suggested that these observations were instead driven by variable fucosylation $(51,53)$. The observation that bisected glycans cannot subsequently become fucosylated appears to have resulted in some confounding of cause and effect with respect to the role of bisection (54).

Nor was there an impact associated with variable terminal sialic acid content (Figures 2C, 3). Again, while some studies have suggested that sialic acid influences receptor binding affinity
A
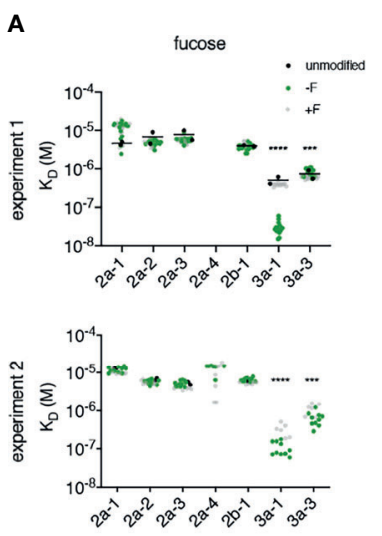

B
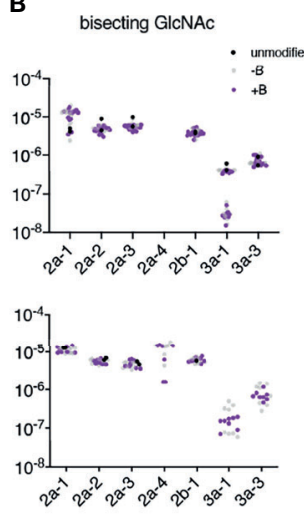

C

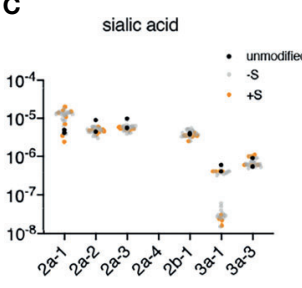

\section{D}
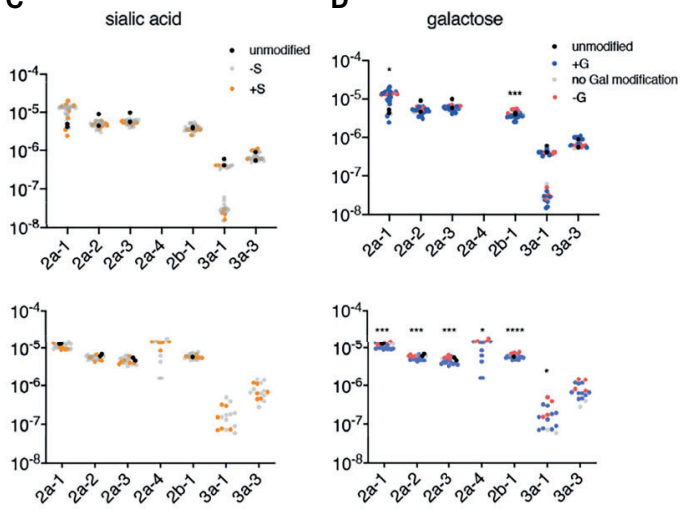

FIGURE 2 | Affinity of rhesus macaque FCyRs for a panel of human IgG1 glycovariants. Equilibrium dissociation constants (K $K_{D}$ ) of rhesus macaque alleles having unique extracellular domains observed in two independent experiments (rows). Within each experiment, glycovariants were printed in replicate and each replicate is plotted. Results are presented such that each panel emphasizes a different category of glycomodification, including variable fucosylation ( $F$ ) (A), bisecting $\mathrm{N}$-Acetylglucosamine (B) (B), sialylation (S) (C), and galactosylation (G) (D). A natively glycosylated preparation (black) is plotted along with variants with (+) or lacking (-) the glycan emphasized in that panel. Statistically significant differences were tested using an unpaired t test comparing glycovariants with $(+)$ and without $(-)$ the modification $\left({ }^{*} \mathrm{p}<\right.$ $\left.0.05,{ }^{\star \star \star} \mathrm{p}<0.0005,{ }^{\star \star \star \star} \mathrm{p}<0.0001\right)$. 


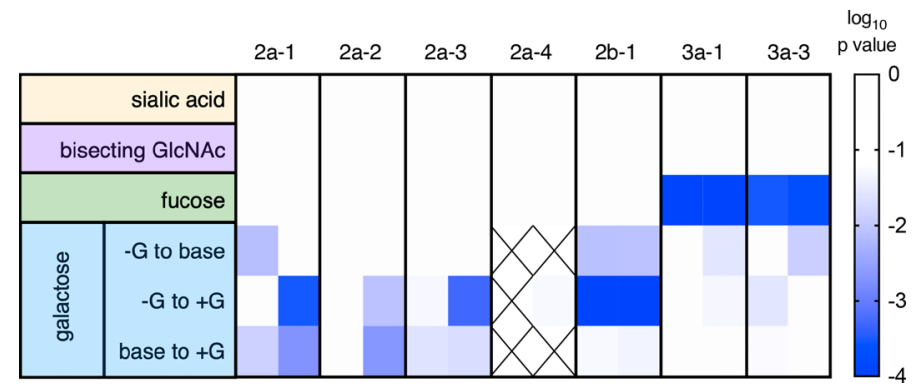

FIGURE 3 | Summary of receptor affinity differences. Statistical significance of differences in affinity associated with variable glycosylation. Glycan modifications are tabulated by row and receptors by column, for each of the two independent experimental runs. Confidence in differences is indicated in color. Crosshatches indicate missing data. The effect of varying (+ versus -) sialic acid, bisecting GlcNAc, and fucose were evaluated by unpaired t test, and for galactose [+G, unmodified (base), and -G] with an ordinary one-way ANOVA corrected for multiple comparisons.

$(55,56)$, others have reported contradictory results $(30,57)$. Using this same well-characterized panel of glycovariants, variation in sialic acid content between 12-64\% appeared to have essentially no general effect on binding affinity across diverse human Fc $\gamma \mathrm{R}$ (51).

Further mirroring their human counterparts, rhesus macaque Fc $\gamma$ Rs had marginally, but often statistically significantly, heightened affinities for IgG with increased levels of galactosylation (Figures 2D, 3). To address these differences with improved resolution, analysis of the effect of variable galactosylation when fucose, sialic acid, and bisecting GlcNAc were held constant were analyzed in paired comparisons (Figure 4). As in the global data analysis, both experimental data sets showed a small but reproducible improvement to FcyRII binding affinity with increasing galactose content when other glycan attributes such as extent of fucosylation or bisection were held constant. These results are consistent with the phenotype observed in humans, where increasing galactose content improved affinity in a small but consistent manner among the low affinity FcyRs $(30,51)$. Similar

\section{FcyR2}

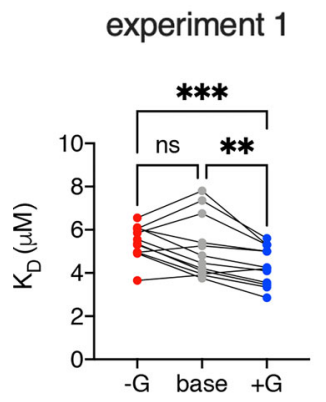

experiment 2

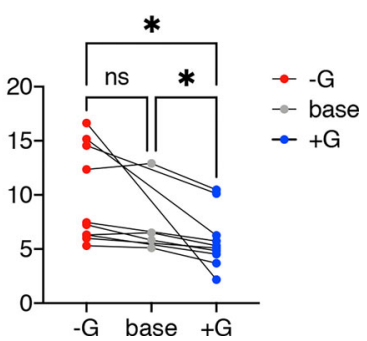

FIGURE 4 | Increased galactosylation is associated with improved affinity for FcyRll. The effect of increased and decreased galactose content on binding to FcyRll variants among IgG Fc glycotypes for which other glycan characteristics (e.g., fucosylation, sialylation, bisection) were held constant. Statistically significant differences were tested using a mixed effect model with Tukey's test of multiple comparisons $\left({ }^{\star} p<0.05\right.$, ${ }^{\star *} p<0.01$, ${ }^{\star \star \star} p<0.001$ ). ns, not significant. paired analysis of fucose, bisecting GlcNAc, and sialic acid showed a small but statistically significant enhancement of binding affinity to FcyRII among otherwise matched but variably bisected variants when data from all FcyRII receptors and both experiments were considered (Supplemental Figure 1). However, this relationship was not observed to hold in both individual experimental replicates.

Because the effect of variable fucose content is of clinical relevance in both natural immune responses (19-24) and in optimization of antibody therapy $(31,53)$, we further probed this aspect of RM receptor binding profiles with additional antibody specificities. Rhesusized antibody to CD20 engineered to lack fucose (Supplemental Figure 2) showed improved binding affinity to RM FcyRIII, as did a Dual Variable Domain (DVD) format bispecific (Figure 5) that was similarly modified to reduce fucose content (Supplemental Figure 3). These experiments show that fucose effect is consistent across both rhesus and human IgG1 Fc domains in the context of distinct antibody specificities and even formats. Indeed, the slowed dissociation rate of afucosylated IgG Fc forms was apparent across data collected in this study, including the experiment for which that effect was obscured by concomitant changes to the association rate for FcyRIIIa-3 that appeared to affect the equilibrium affinities reported here. Importantly, the functional consequences of improved Fc $\gamma$ RIII binding afforded by afucosylation are well established in mice and humans, where improvements in ADCC activity are readily observed to result [summarized in (58)]. While it appears that similar observations have yet to be reported in assays conducted with macaque effecter cells, whose receptor expression profiles are poorly defined and genetic diversity in receptors is extensive, the same glycosylation site associated with this phenotype is conserved in rhesus FcyRIII allotypes. The lack of this glycosylation site in other Fc $\gamma R$ (e.g.: Fc $\gamma R I$ and Fc $\gamma R I I)$ explains the receptor-specific nature of the "fucose effect".

Lastly, to begin to further generalize these observations about glycan binding preferences beyond the human IgG1 backbone, we analyzed serum IgG glycoprevalences among a small set of healthy $\mathrm{RM}$, and investigated relationships between galactose and fucose content and binding to RM Fc $\gamma \mathrm{R}$. Though confidence in correlative relationships between glycan profiles and receptor binding signals are limited by small sample size and the potential effect of differing 

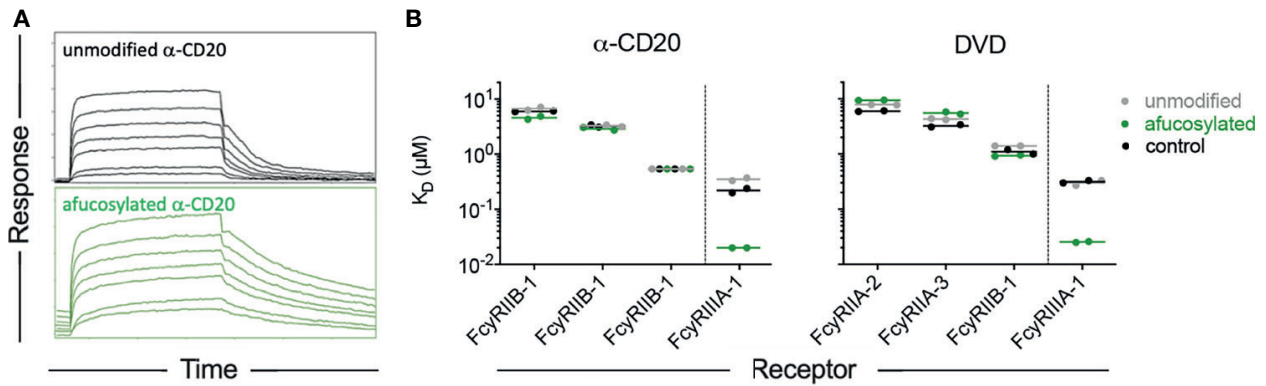

FIGURE 5 | The fucose effect is generalizable across antibodies but not receptors. (A) Representative sensorgrams showing association and dissociation profiles of RM FcgRllla-3 from unmodified and afucosylated forms of a rhesusized version of rituximab. (B) Equilibrium binding affinities of CDR grafted CD20-specific antibodies with rhesus IgG1 Fc domains (left), and a dual variable domain (DVD) bispecific antibody (right) in unmodified and afucosylated forms, and in comparison to an unmodified rhesus IgG1 antibody of a differing specificity (control).

levels of serum IgG between animals, increased binding of serum samples with greater levels of Fc galactosylation was observed across diverse FcyRII and FcyRIII allotypes, as was the effect of reduced fucosylation for Fc $\gamma$ RIII (Figure 6). Collectively, these observations support further generalization of the effects these glycoprofiles have on Fc $\gamma \mathrm{R}$ binding to polyclonal pools of mixed specificity, light chain usage, and subclasses of rhesus macaque IgG.

\section{CONCLUSIONS}

This work establishes that the low affinity Fc $\gamma$ receptors of RM demonstrate preferences for glycoforms of human IgG1 that largely mirror that of their human equivalents. Rhesus macaques therefore likely serve as an appropriate model for the evaluation of glycoengineered human antibodies. While the panel of glycovariants focused on human IgG1, this subclass is overwhelmingly represented among therapeutic monoclonal antibodies, and where evaluated, the glycan preferences appear to hold across human IgG subclasses $(32,59)$. We show here that the effect of fucose on RM FcyRIII recognition is generalizable across both human and rhesus monoclonal antibodies with distinct variable domains, a dual variable domain bispecific construct, and to polyclonal rhesus serum IgG. These results have important implications for the use of RM to study recombinant glycoengineered antibodies in preclinical and mechanistic studies of antibody therapies, as well as in attempting to relate antibody glycotypes raised in response to vaccination (60-62) or via vectored antibody delivery (63), to in vitro effector activities or in vivo outcomes.

\section{METHODS}

\section{Protein Expression and Purification}

The engineering and characterization of the variably glycosylated panel of anti-TNP human IgG1s $(50,51)$ and rhesus macaque Fc $\gamma$ Rs (38) have been described previously. These modifications include manipulation of fucose (F), bisecting GlcNAc (B), sialic acid (S), and galactose $(\mathrm{G})$ content (Supplemental Table 1). Unmodified antiCD20 [anti-CD20 (2B8R1), Nonhuman Primate Reagent Resource Cat\# PR-2287, RRID: AB_2716323] and afucosylated anti-CD20 [anti-CD20 (2B8R1F8), Nonhuman Primate Reagent Resource Cat\# PR-8288, RRID: AB_2819341] were derived from rituximab and grafted into rhesus variable regions. Representative mass spectrometry-based glycoprofiles of these reagents are shown in Supplemental Figure 2. Unmodified and afucosylated forms of an $\mathrm{HIV}$-specific double variable domain bispecific $\mathrm{Ab}$ that binds to both gp120 and gp41 of the envelope protein through fusion of CD4 (d2) with gp41-specific 7B2 monoclonal antibody linked through the H4 linker CD4 (d2)-H4-7B2 $(64,65)$ were constitutively expressed in either wild type or fucosyl-transferase Fut8-/- CHO cells. Unmodified and afucosylated DVDs showed equivalent binding to antigen by ELISA, but differential interaction with biotinylated fucose-specific Lens culinaris lectin, and the human CD16-expressing KHYG-1 Natural Killer cells (66) (kindly provided by Dr. David Evans, Wisconsin National Primate Research Center) (Supplemental Figure 3).

\section{Surface Plasmon Resonance}

Antibodies were covalently coupled to a carboxymethyldextranfunctionalized sensor (CMD200M, Xantec Bioanalytics) using carboiimide chemistry. A Continuous Flow Microspotter (CFM) (Carterra) allowed the complete panel, with replicates, to be printed on a single sensor chip. The sensor surface was activated by a mixture of $10.4 \mathrm{mM}$ EDC (ThermoFisher, 77149) and $2.8 \mathrm{mM}$ sulfo-N-hydroxysuccinimide (ThermoFisher, A39269) formulated in $10 \mathrm{mM}$ MES ( $\mathrm{pH}$ 5.0). Antibodies formulated in $10 \mathrm{mM}$ sodium acetate ( $\mathrm{pH}$ 5.0) at 50 and $100 \mathrm{nM}$ were applied to the activated regions for 10 minutes. The regions were then washed with sodium acetate for 5 minutes. Unreacted substrate was capped using $1 \mathrm{M}$ ethanolamine (Sigma-Aldrich, 15014-100ML) applied by the flow cell of the imaging-based surface plasmon resonance instrument (SPRi) (MX96, IBIS Technologies). Remaining ligand was removed and the overall capacity of the sensor tested using successive injections ( 5 rounds in total) of $25 \mu \mathrm{g} / \mathrm{mL}$ anti-human $\mathrm{Fc}$ and $10 \mathrm{mM}$ glycine ( $\mathrm{pH} 3.0)$. 
A

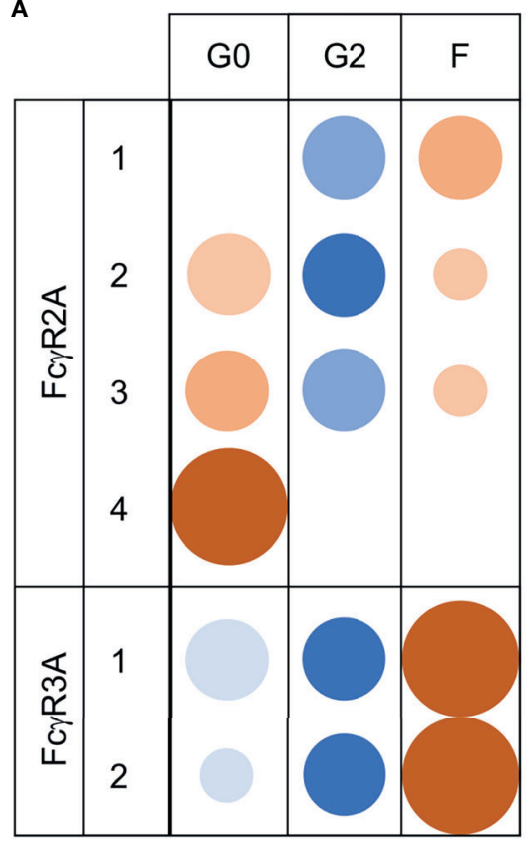

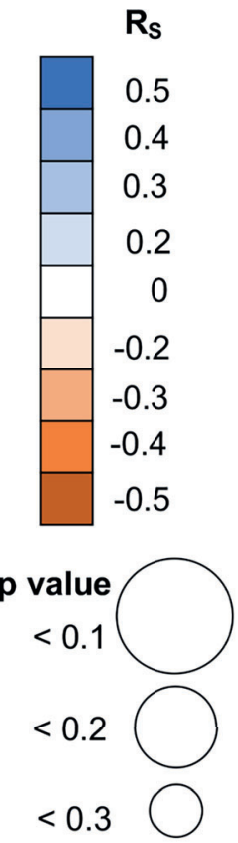

B
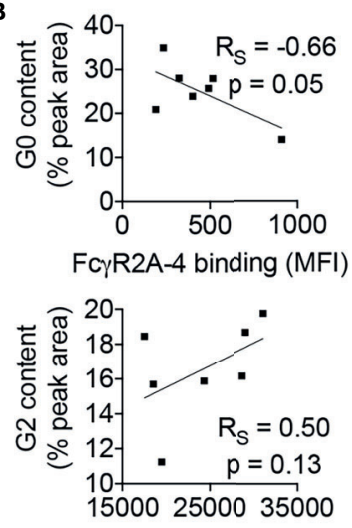

FC $\gamma$ R2A-2 binding (MFI)

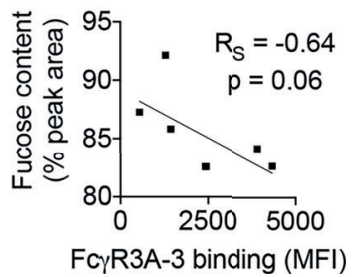

FIGURE 6 | Similar FcyR binding glycopreferences are observed for RM serum IgG. (A) Correlations of receptor binding signal in multiplex assay and glycan species

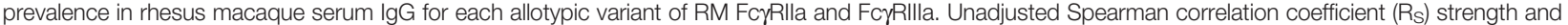
direction are indicated in color, and confidence ( $p$ value) in size. (B) Exemplary scatter plots of relatively stronger correlative relationships between relative galactose and fucose content (\% peak area) in relation to FcyR binding median fluorescent intensity (MFI). Correlation coefficients and exact $\mathrm{p}$ values are indicated in inset.

The Fc receptor analytes were formulated at $20 \mu \mathrm{M}$ in a running buffer consisting of $1 \mathrm{x}$ phosphate buffered saline containing $0.05 \%$ Tween 20. Each receptor was tested over an 8-point series of 1:3 dilutions, running from the lowest concentration to the highest. Association was measured over a 5-minute period before switching the flow cell to running buffer to capture 5 minutes of dissociation. Two blank injections of the running buffer following each receptor series were sufficient to completely dissociate these low-affinity analytes and prepare the sensor for the next receptor.

Raw data was processed using SprintX (IBIS Technologies). The background signal of the nearest unconjugated interspot was subtracted from the adjacent regions of interest to account for bulk shift and non-specific binding. The blank injection immediately preceding each series of receptor was also subtracted from each concentration of receptor. Equilibrium affinity values $\left(\mathrm{K}_{\mathrm{D}}\right)$ for each receptor-glycovariant pair were calculated in Scrubber 2 (BioLogic Software) using the average signal during a ten-second window at the end of the association phase when the system had reached equilibrium. The maximum response (Rmax) predicted for a saturated system was calculated for each region of interest. Regions with an Rmax of less than 25 were discarded for insufficient signal.

\section{Rhesus Serum IgG Receptor Binding and Glycan Analysis}

Serum samples from seven healthy rhesus macaques were profiled for binding to rhesus Fc $\gamma \mathrm{R}$-conjugated fluorescent beads in a multiplexed assay (67). Briefly, recombinant rhesus FcyR were covalently coupled to uniquely fluorescently coded magnetic microspheres, incubated in dilute serum, and bound antibody was detected with a phycoerythinconjugated anti-IgG detection antibody prior to data acquisition on a Luminex FlexMap. Median fluorescent intensities were reported for each sample for each Fc $\gamma$ R.

For glycan analysis, rhesus macaque $\operatorname{IgG}$ was purified from serum via Melon Gel (manufacturer), followed by digestion with both SpeB and IdeA enzymes (Genovis), and purification of cleaved Fc domains by Protein A affinity chromatography (GE Life Sciences), each according to the manufacturer's recommendations. IgG glycan analysis was performed as described previously (68). Briefly, purified Fc was treated with PNGase F (New England Biolabs). Subsequently, protein was precipitated with ethanol and released glycans were evaporatively concentrated prior to fluorescent labeling with 2-aminobenzamide. After washing and removal of excess dye, glycans were analyzed using HILIC HPLC on a 1503 2-mm TSKgel Amide-80 column (Tosoh Bioscience) with 3-mm packing material on a 1200 series HPLC (Agilent Technologies). Peak identities were confirmed via use of a glycan standard (Ludger). Quantification by area-underthe-curve analysis was performed with ChemStation software (Agilent Technologies).

\section{Statistical Analysis}

Statistical analysis was performed in Graphpad Prism version 9. Global comparisons (Figure 2) of glycovariants with (+) and 
without (-) fucose, bisecting GlcNAc, and sialic acid modifications were evaluated for each individual receptor allotype by $t$ test. Galactose content, which was alternatively increased, unmodified, or decreased, was evaluated by one-way ANOVA adjusted for multiple comparisons according to the procedure of Benjamini, Krieger, and Yekutieli. Paired comparisons (Figure 4 and Supplemental Figure 1) of glycovariants with and without fucose, bisecting GlcNAc, and sialic acid modifications but for which other glycan modifications were held constant (i.e.: for fucose content, $+\mathrm{G}$ was paired with $-\mathrm{F}+\mathrm{G}$, and $+\mathrm{G}+\mathrm{S}$ was paired with $-\mathrm{F}+\mathrm{G}+\mathrm{S}$ ) were evaluated by paired t test across of FcyRII types and allotypes and FcyRIII allotypes. Paired comparisons evaluating the effect of variable galactosylation were evaluated using a mixed effect model with Tukey's test of multiple comparisons, comparing the effect of each galactose characteristic $(+G$, unmodified $G$, and $-G)$ when other modifications (F, B, and S)) were held constant. Strength and direction of relationships between Fc glycoform prevalences in rhesus serum IgG and Fc $\gamma \mathrm{R}$ binding signals were evaluated by Spearman's rank correlation coefficient and statistic.

\section{DATA AVAILABILITY STATEMENT}

The raw data supporting the conclusions of this article will be made available by the authors, without undue reservation.

\section{REFERENCES}

1. Schroeder HWJr., Cavacini L. Structure and Function of Immunoglobulins. J Allergy Clin Immunol (2010) 125(2 Suppl 2):S41-52. doi: 10.1016/ j.jaci.2009.09.046

2. Jennewein MF, Alter G. The Immunoregulatory Roles of Antibody Glycosylation. Trends Immunol (2017) 38(5):358-72. doi: 10.1016/ j.it.2017.02.004

3. Bakovic MP, Selman MH, Hoffmann M, Rudan I, Campbell H, Deelder AM, et al. High-Throughput IgG Fc N-Glycosylation Profiling by Mass Spectrometry of Glycopeptides. J Proteome Res (2013) 12(2):821-31. doi: $10.1021 / \mathrm{pr} 300887 \mathrm{z}$

4. Dwek RA. Biological Importance of Glycosylation. Dev Biol Stand (1998) 96:43-7. doi: 10.1007/978-94-011-5288-4_1

5. Chen G, Wang Y, Qiu L, Qin X, Liu H, Wang X, et al. Human IgG FcGlycosylation Profiling Reveals Associations With Age, Sex, Female Sex Hormones and Thyroid Cancer. J Proteomics (2012) 75(10):2824-34. doi: 10.1016/j.jprot.2012.02.001

6. Keusch J, Levy Y, Shoenfeld Y, Youinou P. Analysis of Different Glycosylation States in IgG Subclasses. Clin Chim Acta (1996) 252(2):147-58. doi: 10.1016/ 0009-8981(96)06326-7

7. Parekh R, Roitt I, Isenberg D, Dwek R, Rademacher T. Age-Related Galactosylation of the N-Linked Oligosaccharides of Human Serum IgG. J Exp Med (1988) 167(5):1731-6. doi: 10.1084/jem.167.5.1731

8. Rook GA, Steele J, Brealey R, Whyte A, Isenberg D, Sumar N, et al. Changes in IgG Glycoform Levels Are Associated With Remission of Arthritis During Pregnancy. J Autoimmun (1991) 4(5):779-94. doi: 10.1016/0896-8411(91) 90173-A

9. Shikata K, Yasuda T, Takeuchi F, Konishi T, Nakata M, Mizuochi T. Structural Changes in the Oligosaccharide Moiety of Human IgG With Aging. Glycoconj J (1998) 15(7):683-9. doi: 10.1023/A:1006936431276

10. van de Geijn FE, Wuhrer M, Selman MH, Willemsen SP, de Man YA, Deelder AM, et al. Immunoglobulin G Galactosylation and Sialylation Are Associated With Pregnancy-Induced Improvement of Rheumatoid Arthritis and the

\section{AUTHOR CONTRIBUTIONS}

Conceptualization, AC and MA. Investigation, AC, GD, SP, WG, and NO-O. Writing - original draft, AC and MA. Writing review and editing, all authors. Data analysis and curation, AC, NO-O, and MA. Funding acquisition, GV and MA. All authors contributed to the article and approved the submitted version.

\section{FUNDING}

This work was supported in part by the NIGMS and the NIAID R01 AI131975, NIAID P01 AI120756, AI136758, and NIH NCI supplement to 2P30 CA 023108-41, the BioMT Molecular Tools Core supported by NIGMS COBRE award P20-GM113132. Reagents provided by the NIH Nonhuman Primate Reagent Resource were supported by the awards P40 OD028116 (ORIP) and U24 AI126683 (NIAID).

\section{SUPPLEMENTARY MATERIAL}

The Supplementary Material for this article can be found online at: https://www.frontiersin.org/articles/10.3389/fimmu.2021. 754710/full\#supplementary-material

Postpartum Flare: Results From a Large Prospective Cohort Study. Arthritis Res Ther (2009) 11(6):R193. doi: 10.1186/ar2892

11. Yamada E, Tsukamoto Y, Sasaki R, Yagyu K, Takahashi N. Structural Changes of Immunoglobulin G Oligosaccharides With Age in Healthy Human Serum. Glycoconj J (1997) 14(3):401-5. doi: 10.1023/A:1018582930906

12. Lauc G, Huffman JE, Pucic M, Zgaga L, Adamczyk B, Muzinic A, et al. Loci Associated With N-Glycosylation of Human Immunoglobulin G Show Pleiotropy With Autoimmune Diseases and Haematological Cancers. PloS Genet (2013) 9(1):e1003225. doi: 10.1371/journal.pgen.1003225

13. Novokmet M, Lukic E, Vuckovic F, Ethuric Z, Keser T, Rajsl K, et al. Changes in IgG and Total Plasma Protein Glycomes in Acute Systemic Inflammation. Sci Rep (2014) 4:4347. doi: 10.1038/srep04347

14. Selman MH, de Jong SE, Soonawala D, Kroon FP, Adegnika AA, Deelder AM, et al. Changes in Antigen-Specific IgG1 Fc N-Glycosylation Upon Influenza and Tetanus Vaccination. Mol Cell Proteomics (2012) 11(4):M111 014563. doi: 10.1074/mcp.M111.014563

15. Kao D, Lux A, Schaffert A, Lang R, Altmann F, Nimmerjahn F. IgG Subclass and Vaccination Stimulus Determine Changes in Antigen Specific Antibody Glycosylation in Mice. Eur J Immunol (2017) 47(12):2070-9. doi: 10.1002/ eji.201747208

16. Mahan AE, Jennewein MF, Suscovich T, Dionne K, Tedesco J, Chung AW, et al. Antigen-Specific Antibody Glycosylation Is Regulated via Vaccination. PloS Pathog (2016) 12(3):e1005456. doi: 10.1371/journal.ppat.1005456

17. Nose M, Wigzell H. Biological Significance of Carbohydrate Chains on Monoclonal Antibodies. Proc Natl Acad Sci U S A (1983) 80(21):6632-6. doi: $10.1073 /$ pnas.80.21.6632

18. Mimura Y, Sondermann P, Ghirlando R, Lund J, Young SP, Goodall M, et al. Role of Oligosaccharide Residues of IgG1-Fc in Fc Gamma RIIb Binding J Biol Chem (2001) 276(49):45539-47. doi: 10.1074/jbc.M107478200

19. Ackerman ME, Crispin M, Yu X, Baruah K, Boesch AW, Harvey DJ, et al. Natural Variation in Fc Glycosylation of HIV-Specific Antibodies Impacts Antiviral Activity. J Clin Invest (2013) 123(5):2183-92. doi: 10.1172/JCI65708

20. Larsen MD, de Graaf EL, Sonneveld ME, Plomp HR, Nouta J, Hoepel W, et al. Afucosylated IgG Characterizes Enveloped Viral Responses and Correlates With COVID-19 Severity. Science (2021) 371(6532). doi: 10.1126/science.abc8378 
21. Thulin NK, Brewer RC, Sherwood R, Bournazos S, Edwards KG, Ramadoss NS, et al. Maternal Anti-Dengue IgG Fucosylation Predicts Susceptibility to Dengue Disease in Infants. Cell Rep (2020) 31(6):107642. doi: 10.1016/ j.celrep. 2020.107642

22. Wang TT, Sewatanon J, Memoli MJ, Wrammert J, Bournazos S, Bhaumik SK, et al. IgG Antibodies to Dengue Enhanced for Fcyriiia Binding Determine Disease Severity. Science (2017) 355(6323):395-8. doi: 10.1126/science.aai8128

23. Kapur R, Kustiawan I, Vestrheim A, Koeleman CA, Visser R, Einarsdottir HK, et al. A Prominent Lack of IgG1-Fc Fucosylation of Platelet Alloantibodies in Pregnancy. Blood (2014) 123(4):471-80. doi: 10.1182/blood-2013-09-527978

24. Kapur R, Valle LD, Sonneveld M, Ederveen AH, Visser R, Ligthart P, et al. Low Anti-RhD IgG-Fc-Fucosylation in Pregnancy: A New Variable Predicting Severity in Haemolytic Disease of the Fetus and Newborn. Br J Haematol (2014) 166(6):936-45. doi: 10.1111/bjh.12965

25. Chakraborty S, Gonzalez J, Edwards K, Mallajosyula V, Buzzanco AS, Sherwood R, et al. Proinflammatory IgG Fc Structures in Patients With Severe COVID-19. Nat Immunol (2021) 22(1):67-73. doi: 10.1038/s41590020-00828-7

26. Lu LL, Chung AW, Rosebrock TR, Ghebremichael M, Yu WH, Grace PS, et al. A Functional Role for Antibodies in Tuberculosis. Cell (2016) 167(2):433-43 e14. doi: 10.1016/j.cell.2016.08.072

27. Ho CH, Chien RN, Cheng PN, Liu JH, Liu CK, Su CS, et al. Aberrant Serum Immunoglobulin G Glycosylation in Chronic Hepatitis B Is Associated With Histological Liver Damage and Reversible by Antiviral Therapy. J Infect Dis (2015) 211(1):115-24. doi: 10.1093/infdis/jiu388

28. van Osch TLJ, Nouta J, Derksen NIL, van Mierlo G, van der Schoot E, Wuhrer $\mathrm{M}$, et al. Fc Galactosylation Promotes Hexamerization of Higg1 Leading to Enhanced Classic Complement Activation. J Immunol (2021). doi: 10.4049/ jimmunol.2100399

29. Yamaguchi $Y$, Nishimura M, Nagano M, Yagi H, Sasakawa H, Uchida K, et al. Glycoform-Dependent Conformational Alteration of the Fc Region of Human Immunoglobulin G1 as Revealed by NMR Spectroscopy. Biochim Biophys Acta (2006) 1760(4):693-700. doi: 10.1016/j.bbagen.2005.10.002

30. Subedi GP, Barb AW. The Immunoglobulin G1 N-Glycan Composition Affects Binding to Each Low Affinity Fc Gamma Receptor. MAbs (2016) 8 (8):1512-24. doi: 10.1080/19420862.2016.1218586

31. Shields RL, Lai J, Keck R, O'Connell LY, Hong K, Meng YG, et al. Lack of Fucose on Human IgG1 N-Linked Oligosaccharide Improves Binding to Human Fcgamma RIII and Antibody-Dependent Cellular Toxicity. J Biol Chem (2002) 277(30):26733-40. doi: 10.1074/jbc.M202069200

32. Niwa R, Natsume A, Uehara A, Wakitani M, Iida S, Uchida K, et al. IgG Subclass-Independent Improvement of Antibody-Dependent Cellular Cytotoxicity by Fucose Removal From Asn297-Linked Oligosaccharides. J Immunol Methods (2005) 306(1-2):151-60. doi: 10.1016/j.jim.2005.08.009

33. Bruhns P, Iannascoli B, England P, Mancardi DA, Fernandez N, Jorieux S, et al. Specificity and Affinity of Human Fcgamma Receptors and Their Polymorphic Variants for Human IgG Subclasses. Blood (2009) 113 (16):3716-25. doi: 10.1182/blood-2008-09-179754

34. Brady LJ, Velayudhan J, Visone DB, Daugherty KC, Bartron JL, Coon M, et al. The Criticality of High-Resolution N-Linked Carbohydrate Assays and Detailed Characterization of Antibody Effector Function in the Context of Biosimilar Development. MAbs (2015) 7(3):562-70. doi: 10.1080/ 19420862.2015.1016692

35. Shinkawa T, Nakamura K, Yamane N, Shoji-Hosaka E, Kanda Y, Sakurada M, et al. The Absence of Fucose But Not the Presence of Galactose or Bisecting NAcetylglucosamine of Human IgG1 Complex-Type Oligosaccharides Shows the Critical Role of Enhancing Antibody-Dependent Cellular Cytotoxicity. J Biol Chem (2003) 278(5):3466-73. doi: 10.1074/jbc.M210665200

36. Junttila TT, Parsons K, Olsson C, Lu Y, Xin Y, Theriault J, et al. Superior In Vivo Efficacy of Afucosylated Trastuzumab in the Treatment of HER2Amplified Breast Cancer. Cancer Res (2010) 70(11):4481-9. doi: 10.1158/ 0008-5472.CAN-09-3704

37. Cameron F, McCormack PL. Obinutuzumab: First Global Approval. Drugs (2014) 74(1):147-54. doi: 10.1007/s40265-013-0167-3

38. Chan YN, Boesch AW, Osei-Owusu NY, Emileh A, Crowley AR, Cocklin SL, et al. IgG Binding Characteristics of Rhesus Macaque FcgammaR. J Immunol (2016) 197(7):2936-47. doi: 10.4049/jimmunol.1502252
39. Boesch AW, Osei-Owusu NY, Crowley AR, Chu TH, Chan YN, Weiner JA, et al. Biophysical and Functional Characterization of Rhesus Macaque IgG Subclasses. Front Immunol (2016) 7:589. doi: 10.3389/fimmu.2016.00589

40. Crowley AR, Ackerman ME. Mind the Gap: How Interspecies Variability in IgG and Its Receptors May Complicate Comparisons of Human and NonHuman Primate Effector Function. Front Immunol (2019) 10:697. doi: 10.3389/fimmu.2019.00697

41. Haj AK, Arbanas JM, Yamniuk AP, Karl JA, Bussan HE, Drinkwater KY, et al. Characterization of Mauritian Cynomolgus Macaque FcgammaR Alleles Using Long-Read Sequencing. J Immunol (2019) 202(1):151-9. doi: 10.4049/jimmunol.1800843

42. Grunst MW, Grandea AG3rd, Janaka SK, Hammad I, Grimes P, Karl JA, et al. Functional Interactions of Common Allotypes of Rhesus Macaque FcgammaR2A and FcgammaR3A With Human and Macaque IgG Subclasses. J Immunol (2020) 205(12):3319-32. doi: 10.4049/jimmunol.2000501

43. Raju TS, Briggs JB, Borge SM, Jones AJ. Species-Specific Variation in Glycosylation of IgG: Evidence for the Species-Specific Sialylation and Branch-Specific Galactosylation and Importance for Engineering Recombinant Glycoprotein Therapeutics. Glycobiology (2000) 10(5):477-86. doi: $10.1093 /$ glycob/10.5.477

44. Mahan AE, Tedesco J, Dionne K, Baruah K, Cheng HD, De Jager PL, et al. A Method for High-Throughput, Sensitive Analysis of IgG Fc and Fab Glycosylation by Capillary Electrophoresis. J Immunol Methods (2015) 417:34-44. doi: 10.1016/j.jim.2014.12.004

45. Ferrara C, Grau S, Jager C, Sondermann P, Brunker P, Waldhauer I, et al. Unique Carbohydrate-Carbohydrate Interactions Are Required for High Affinity Binding Between FcgammaRIII and Antibodies Lacking Core Fucose. Proc Natl Acad Sci U S A (2011) 108(31):12669-74. doi: 10.1073/ pnas. 1108455108

46. Mizushima T, Yagi H, Takemoto E, Shibata-Koyama M, Isoda Y, Iida S, et al. Structural Basis for Improved Efficacy of Therapeutic Antibodies on Defucosylation of Their Fc Glycans. Genes Cells (2011) 16(11):1071-80. doi: 10.1111/j.1365-2443.2011.01552.x

47. Falconer DJ, Subedi GP, Marcella AM, Barb AW. Antibody Fucosylation Lowers the FcgammaRIIIa/CD16a Affinity by Limiting the Conformations Sampled by the N162-Glycan. ACS Chem Biol (2018) 13(8):2179-89. doi: 10.1021/acschembio.8b00342

48. Dekkers G, Bentlage AEH, Plomp R, Visser R, Koeleman CAM, Beentjes A, et al. Conserved FcgammaR- Glycan Discriminates Between Fucosylated and Afucosylated IgG in Humans and Mice. Mol Immunol (2018) 94:54-60. doi: 10.1016/j.molimm.2017.12.006

49. Moldt B, Shibata-Koyama M, Rakasz EG, Schultz N, Kanda Y, Dunlop DC, et al. A Nonfucosylated Variant of the Anti-HIV-1 Monoclonal Antibody B12 has Enhanced FcgammaRIIIa-Mediated Antiviral Activity In Vitro But Does Not Improve Protection Against Mucosal SHIV Challenge in Macaques. J Virol (2012) 86(11):6189-96. doi: 10.1128/JVI.00491-12

50. Dekkers G, Plomp R, Koeleman CA, Visser R, von Horsten HH, Sandig V, et al. Multi-Level Glyco-Engineering Techniques to Generate IgG With Defined Fc-Glycans. Sci Rep (2016) 6:36964. doi: 10.1038/srep36964

51. Dekkers G, Treffers L, Plomp R, Bentlage AEH, de Boer M, Koeleman CAM, et al. Decoding the Human Immunoglobulin G-Glycan Repertoire Reveals a Spectrum of Fc-Receptor- and Complement-Mediated-Effector Activities. Front Immunol (2017) 8:877. doi: 10.3389/fimmu.2017.00877

52. Hodoniczky J, Zheng YZ, James DC. Control of Recombinant Monoclonal Antibody Effector Functions by Fc N-Glycan Remodeling In Vitro. Biotechnol Prog (2005) 21(6):1644-52. doi: 10.1021/bp050228w

53. Shinkawa T, Nakamura K, Yamane N, Shoji-Hosaka E, Kanda Y, Sakurada M, et al. The Absence of Fucose But Not the Presence of Galactose or Bisecting N -Acetylglucosamine of Human IgG1 Complex-Type Oligosaccharides Shows the Critical Role of Enhancing Antibody-Dependent Cellular Cytotoxicity. J Biol Chem (2002) 278(5):3466-73. doi: 10.1074/jbc.RA118.005294

54. Ferrara C, Brunker P, Suter T, Moser S, Puntener U, Umana P. Modulation of Therapeutic Antibody Effector Functions by Glycosylation Engineering: Influence of Golgi Enzyme Localization Domain and Co-Expression of Heterologous Beta1, 4-N-Acetylglucosaminyltransferase III and Golgi Alpha-Mannosidase II. Biotechnol Bioeng (2006) 93(5):851-61. doi: 10.1002/ bit.20777 
55. Anthony RM, Nimmerjahn F, Ashline DJ, Reinhold VN, Paulson JC, Ravetch JV. Recapitulation of IVIG Anti-Inflammatory Activity With a Recombinant IgG Fc. Science (2008) 320(5874):373-6. doi: 10.1126/science.1154315

56. Kaneko Y, Nimmerjahn F, Ravetch JV. Anti-Inflammatory Activity of Immunoglobulin G Resulting From Fc Sialylation. Science (2006) 313 (5787):670-3. doi: 10.1126/science.1129594

57. Yu X, Baruah K, Harvey DJ, Vasiljevic S, Alonzi DS, Song BD, et al. Engineering Hydrophobic Protein-Carbohydrate Interactions to Fine-Tune Monoclonal Antibodies. J Am Chem Soc (2013) 135(26):9723-32. doi: 10.1021/ja4014375

58. Pereira NA, Chan KF, Lin PC, Song Z. The "Less-is-More" in Therapeutic Antibodies: Afucosylated Anti-Cancer Antibodies With Enhanced AntibodyDependent Cellular Cytotoxicity. MAbs (2018) 10(5):693-711. doi: 10.1080/ 19420862.2018.1466767

59. Bruggeman CW, Dekkers G, Bentlage AEH, Treffers LW, Nagelkerke SQ, Lissenberg-Thunnissen S, et al. Enhanced Effector Functions Due to Antibody Defucosylation Depend on the Effector Cell Fcgamma Receptor Profile. J Immunol (2017) 199(1):204-11. doi: 10.4049/jimmunol.1700116

60. Barouch DH, Alter G, Broge T, Linde C, Ackerman ME, Brown EP, et al. Protective Efficacy of Adenovirus/Protein Vaccines Against SIV Challenges in Rhesus Monkeys. Science (2015) 349(6245):320-4. doi: 10.1126/science.aab3886

61. Miller-Novak LK, Das J, Musich TA, Demberg T, Weiner JA, Venzon DJ, et al. Analysis of Complement-Mediated Lysis of Simian Immunodeficiency Virus (SIV) and SIV-Infected Cells Reveals Sex Differences in Vaccine-Induced Immune Responses in Rhesus Macaques. J Virol (2018) 92(19). doi: 10.1128/JVI.00721-18

62. Vaccari M, Gordon SN, Fourati S, Schifanella L, Liyanage NP, Cameron M, et al. Adjuvant-Dependent Innate and Adaptive Immune Signatures of Risk of SIVmac251 Acquisition. Nat Med (2016) 22(7):762-70. doi: 10.1038/nm.4105

63. Welles HC, Jennewein MF, Mason RD, Narpala S, Wang L, Cheng C, et al. Vectored Delivery of Anti-SIV Envelope Targeting mAb via AAV8 Protects Rhesus Macaques From Repeated Limiting Dose Intrarectal Swarm SIVsmE660 Challenge. PloS Pathog (2018) 14(12):e1007395. doi: 10.1371/journal.ppat.1007395

64. Craig RB, Summa CM, Corti M, Pincus SH. Anti-HIV Double Variable Domain Immunoglobulins Binding Both Gp41 and Gp120 for Targeted Delivery of Immunoconjugates. PloS One (2012) 7(10):e46778. doi: 10.1371/ journal.pone. 0046778
65. Pincus SH, Craig RB, Weachter L, LaBranche CC, Nabi R, Watt C, et al. Bispecific Anti-HIV Immunoadhesins That Bind Gp120 and Gp41 Have Broad and Potent HIV-Neutralizing Activity. Vaccines (2021) 9(774). doi: 10.3390/vaccines 9070774

66. Alpert MD, Harvey JD, Lauer WA, Reeves RK, Piatak MJr., Carville A, et al. ADCC Develops Over Time During Persistent Infection With LiveAttenuated SIV and Is Associated With Complete Protection Against SIV (mac)251 Challenge. PloS Pathog (2012) 8(8):e1002890. doi: 10.1371/ journal.ppat. 1002890

67. Boesch AW, Brown EP, Cheng HD, Ofori MO, Normandin E, Nigrovic PA, et al. Highly Parallel Characterization of IgG Fc Binding Interactions. MAbs (2014) 6(4):915-27. doi: 10.4161/mabs.28808

68. Storcksdieck genannt Bonsmann M, Niezold T, Temchura V, Pissani F, Ehrhardt K, Brown EP, et al. Enhancing the Quality of Antibodies to HIV-1 Envelope by GagPol-Specific Th Cells. J Immunol (2015) 195(10):4861-72. doi: 10.4049/jimmunol.1501377

Conflict of Interest: WG was employed by Antagen Pharmaceuticals Inc.

The remaining authors declare that the research was conducted in the absence of any commercial or financial relationships that could be construed as a potential conflict of interest.

Publisher's Note: All claims expressed in this article are solely those of the authors and do not necessarily represent those of their affiliated organizations, or those of the publisher, the editors and the reviewers. Any product that may be evaluated in this article, or claim that may be made by its manufacturer, is not guaranteed or endorsed by the publisher.

Copyright $\odot 2021$ Crowley, Osei-Owusu, Dekkers, Gao, Wuhrer, Magnani, Reimann, Pincus, Vidarsson and Ackerman. This is an open-access article distributed under the terms of the Creative Commons Attribution License (CC BY). The use, distribution or reproduction in other forums is permitted, provided the original author(s) and the copyright owner(s) are credited and that the original publication in this journal is cited, in accordance with accepted academic practice. No use, distribution or reproduction is permitted which does not comply with these terms. 